\title{
Research Progress on Solidification of Soft Muddy Soil
}

\author{
Qianwen Wang ${ }^{1}$, Lichao $\mathrm{He}^{2}$, Hongna Yang ${ }^{2}$, Futao $\mathrm{Jiao}^{2}$, Feng Tan ${ }^{1}$, and Xinming Zhao ${ }^{1, *}$ \\ ${ }^{1}$ Nanjing University of Aeronautics and Astronautics, Department of civil engineering, Nanjing, China, 210016 \\ ${ }^{2}$ STECOL CORPORATION, Tianjin, 300384
}

\begin{abstract}
A large number of literatures which had reported soft muddy soil stabilization were reviewed to review the present status and classification of soft muddy soil solidifying materials, summarize and analyze the solidifying mechanism of various solidifying materials in this paper. The results show that the soft muddy soil solidification which has significant economic, environmental and social benefit has wide application potential. Meanwhile, the questions need to be solved at present and suggestions of soft muddy soil solidification have been put forward.
\end{abstract}

\section{Introduction}

The soft muddy soil is considered that unconsolidated soft fine grained soils or very fine soil is deposited and formed in a standing or slow flowing water environment by physical, chemistry and biological effects, which belongs to modern recent sediments. According to natural pore ratio, the soft muddy soil can be divided into the silt (natural moisture content is greater than the liquid limit and natural pore ratio is equal to or greater than 1.5) and the mucky soil (natural moisture content is greater than the liquid limit and natural pore ratio is greater than 1.0 but less than 1.5) ${ }^{[1]}$. It is widely distributed in inland areas along lakes, rivers and southeastern coastal areas in China. With the rapid development of the construction project and the need of opening up, there is no way to avoid silt and mucky soil in engineer. In Jiangsu province, for example, over 3.5 billion cubic meters soft muddy soil was produced between 2003 and $2014^{[2]}$.

When encountering soft muddy soil in engineering construction, traditional methods, such as throw fill disposal, dehydration, heat treatment and blow-filled land reclamation, are limited in practical engineering application, such as, large occupation of engineering site, great increase of economic cost, secondary pollution, project delay and unsatisfactory construction effect, etc. The solidification treatment technology of soft muddy soil refers to adding solidifying materials for its characteristic to the soft muddy soil to improve its physical and mechanical properties and to meet the engineering requirements. Moreover, the solidified soft muddy soil performs well and has low cost. It has obvious advantages such as wide range for application, high early strength, adjustable strength and available local materials.

\section{Engineering properties of soft muddy soil}

The soft muddy soil, which is different from general soil, mainly consists of clay. The surface is negatively charged and it has large surface area. So water molecules and cations of surrounding mediums are easy to be absorbed to form absorbed water layers. Therefore, the soft muddy soil has higher natural moisture content and natural pore ratio. Generally speaking, the moisture content of mucky soil is higher than $30 \%$ while silt's is higher than $80 \%$. The shear strength, considered as an important index of soil mechanical properties, is greatly affected by moisture content. Huang Kun ${ }^{[3]}$ conducted experimental studies and found that the shear strength, cohesion and internal friction angle of soil wound reduce with the increase of moisture content. Therefore, high moisture content is the fundamental factor to the low strength of soft muddy soil.

Being rich in organic matter is another important engineering property of soft muddy soil. Organic matter in soil mainly includes fulvic acid and humic acid, which will affect the properties of soil ${ }^{[4]}$. The hydrophily, plasticity and compressibility of soil will grow larger and the water permeanility and shear strength will grow lower while the content of organic matter is higher ${ }^{[5]}$. At the same time, organic matter is also an important factor affecting the solidification effect of soft muddy soil. Tests showed that organic matter seriously affected the development of the strength of solidified soil ${ }^{[6]}$. For cement solidified soil, the acids in organic matter will reduce its alkalinity, so that the hydration reaction during the solidification cannot produce the calcium silicate hydrate, which plays an important role in the strength growth of solidified soil. Fan Zhaoping ${ }^{[7]}$ revealed the influence law of organic matter on the solidification effect through the solidification tests of different organic

\footnotetext{
* Corresponding author: xmzhao@nuaa.edu.cn
} 
matter contents. It is believed that there is a limit value of organic matter content for the effect to the solidified soil, which is $4.3 \%$. When exceeding this value, the increase of organic matter content on longer has a greater impact on the solidification.

\section{Research status of soft muddy soil solidification technology}

\subsection{Solidifying material classification}

There are many kinds of solidifying materials, which are generally classified according to their appearance and major ingredient. According to appearance, it can be divided into solid solidify agent and liquid solidify agent. According to major ingredient, it can be divided into inorganic class, organic class, biological enzyme class and compound class.

\subsubsection{Inorganic solidify agent}

Inorganic solidify agents are generally solid powder, such as cement, quicklime, coal ash and several kinds of industrial waste. Due to its low cost and good strength stability, this kind of solidify agent is most widely used. Cement is the most commonly used and main solidify agent. In general, such solidify agent reacts with water in the soil to hydrolyze and hydrate to form a mixture of calcium hydroxide, hydrated calcium carbonate and cement bacillus when used into solidifying. Some of these hydras will continue to harden spontaneously. As the age grows, stable crystalline hydrates insoluble in water gradually generate in the soil, which improve the strength of solidified soil. However, this kind of solidify agent has disadvantages in engineering application, such as consumption, high transportation cost and low early strength.

\subsubsection{Organic solidify agent}

Organic solidify agents mainly include water glass, epoxy resin, lignin and high-molecular polymer. This solidify agent makes the soil particles wrapped by hydrophobic layer through its own ion exchange and no longer absorb the free water in the pore, so that the solidified soil changes from hydrophilic to hydrophobic. Or the agent itself can reinforce the soil through the polymerization reaction under the catalyst, forming new soil structure, improving the engineering property and enhancing the soil strength.

\subsubsection{Biological enzyme solidify agent}

Biological enzyme solidify agent is a kind of protein multienzymatic made from the fermented organic matter. This kind of agent can strengthen the adhesiveness among soil particles to form a water-tight structure through catalysis of biological enzyme and squeezing action of external force.

\subsubsection{Compound solidify agent}

Compound solidify agents are made of two or more different solidify materials according to certain proportion. This kind of agent usually has a distinction between primary solidify agent and activator on chemical composition. When solidifying soft muddy soil, the solidify effect of the single agent is usually not ideal, while compound agent considers the factors affecting the properties and strength of the solidified soil, as well as the economic benefits. Different proportion of various solidify materials and activators are mixed to achieve the most ideal effective solidify material formulation.

\subsection{Research status of solidify materials}

In the early $20^{\text {th }}$ century, soil solidification technology was used to improve the soil in practical engineering in some developed countries and achieved good results. In the 1970s, soil solidification technology was developed deeper by the United States, Japan and other developed countries. Solidify materials from the original cement, lime and coal ash, etc. to soil stabilizer-a new material which is specially used to solidify and has been widely used in road engineering, hydraulic engineering and civil and architectural engineering. Overseas scholars and relevant research institutes have achieved many research achievements in the field of soft muddy soil solidification technology. In 1955, Tomohisa ${ }^{[8]}$ first proposed to apply compound solidify agents-concrete powder, paper pulp, coal ash and cinerite to high moisture content and high organic matter content soft soil. Sezer ${ }^{[9]}$ studied the influence law of the lime and coal ash content on the strength after solidification in a certain area of Turkey through triaxial shear tests and unconfined compressive strength tests. Rose Wright Fox ${ }^{[10]}$ performed contrastive solidifying tests on two kinds of enzyme solidify agents and cement, and the results showed that the enzyme solidify agents had advantages in improving the shear strength of solidified soil, but the cement-stabilized soil had better water resistance. Helene ${ }^{[11]}$ applied lime-cement solidify agent to dredged silt, and analyzed its impact on the compressive property of the solidified silt by changing factors such as the content of agent, normal stress and initial pore ratio.

In the 1990s, solidify agent was introduced into China as a high-tech product. Domestic scholars began to study and explore the physical and mechanical properties of solidify materials and solidified soil. Although started late, ideal research results have been achieved so far.

In terms of inorganic solidify materials, Gao Guorui $^{[12]}$ analyzed the solidifying mechanism of single cement agent and obtained the effect of soft muddy soil composition on the optimum cement content. Wang Wenjun $^{[13]}$ studied the effect of nanometer silica fume content and solidifying age on the compressive strength of cement solidified muddy-silty clay through unconfined compressive strength tests. And he analyzed the mechanism between nanometer silica fume and muddy-silty clay and the applicability of 
nanometer silica fume solidify agent. Zhuang Xinshan ${ }^{[14]}$ obtained that the solidification effect of agent with equal cement and lime was better than that of single cement or gypsum. In terms of organic solidify materials, Huang Chunxiang ${ }^{[15]}$ applied cement-water glass to solidify soft muddy soil. Through laboratory tests, it was concluded that there was not only physical absorption but also $\mathrm{s}$ series of chemical reactions between water glass, cement and soil, which improved the strength of solidified soil. Jian Wenbin ${ }^{[16]}$ observed and studied microstructure feature of cement-water glass solidified soft muddy soil at different ages by scanning electron microscopy. The micro mechanism of cement-water glass solidified soft muddy soil was analyzed from physical and chemical aspects. The chemical aspect mainly includes the hydration and hydrolysis reaction of cement itself, the rapid condensation and enhancement of water glass and the interaction between clay particles and cement hydrates. The physical aspect mainly includes the filling effect, cementation effect, reinforcement effect and framework effect of hydrate. Zou $\operatorname{Bin}^{[17]}$ conducted water resistance permeability tests, strength test and model test on calcium acrylate solidified soft muddy soil. It was considered that calcium acrylate was an ideal polymer soft muddy soil solidify material with high consolidation, strength and water resistance. In terms of compound solidify materials, Zhou Mingkai ${ }^{[18]}$ carried out comparative experimental study on the performance of cement and HS soft soil solidify agent combined with $10 \%$ solidify agent. It was shown that the strength of HS solidified soil was $30 \%$ over higher than that of cement, and that the strength growth rate of HS solidified soil was greater than that of cement solidify soil. Huang $\mathrm{Xin}^{[19]}$ conducted solidification tests on two typical soft muddy soil with cement, gypsum and a kind of compound solidify material composed of aluminium expansive components. The results showed that the effect of the compound solidify material was better than that of other two agents.

\subsection{Research status of Solidifying Mechanism}

It is the engineering properties of soft muddy soil determine the importance of the development of solidification countermeasure based on solidifying mechanism and solidify materials, which is also the precondition for the application of solidification technology in practical engineering. In recent decades, scholars at home and abroad have conducted extensive researches on solidifying mechanism of various solidify materials and have obtained a series of results. Ning Jianguo $^{[20]}$ proposed a new solidified soil structure model. Through the solidification test of cement soil, it was concluded that the formation of solidified soil structure and the strength of the solidified soil are based on the consolidation and pore filling of soil particles, and the pore filling plays a significance role in the strength of solidified soil. Aiming at the soft muddy soil with high organic matter content, Shao $\mathrm{Li}^{[4]}$ conducted the laboratory test of strengthening the soft muddy soil in lagoon by cement and coal ash, and analyzed the strength law and deformation law of soil solidified by cement and coal ash. And the solidifying mechanism of coal ash in cement solidified soil was obtained. There were three kinds of effects: morphological effect, active effect and microaggregate effect. Guo Yin ${ }^{[21]}$ studied the influence mechanism of humic acids on cement hydration process in solidified soil starting from the characteristics of humic acid in organic matter. Aiming at the characteristic of high moisture content and high humic acid content of silty soil, the countermeasures for solidifying silty soil were put forward from the points of reducing thickness of double electric layer, adding expansion components, enhancing early strength and soil $\mathrm{PH}$ value, cracking organic macromolecular structure and regulating the activity of cement ions and clay particles. And the compound solidify agent with excellent solidifying effect was developed. Combining the SEM tests and unconfined compressive strength test, the solidifying mechanism of the cemented soil of nanometer silica fume was obtained, which included cementation of cement hydrate, ion exchange effect and secondary reaction of clay particles and the pozzolanic reaction, the filling and cementation effect of nanometer silica fume ${ }^{[13]}$. Zhang Chunlei ${ }^{[22]}$ established the moisture conversion model with the increase of cement content and age in the process of silt solidification based on the law of moisture conversion of silt solidification. The mechanism of silt solidification could be analyzed quantitatively and it was clear that the strength of solidified silt mainly came from the framework effect, the filling effect and the cementation of cement hydrate.

With respect to the research achievement of the present solidifying mechanism, research on the solidifying mechanism of traditional solidify materials such as cement, lime, industrial waste and water glass has tended to reach perfection. Due to the complexity and variability of the composition of the new compound soil solidify agents, its solidifying mechanism still needs further research, and is the focus of future research. The solidifying mechanism of various kinds of main solidify materials is shown in table 1.

Despite the solidifying mechanisms of various kinds of materials are different, but its essence is to improve the soil compactness, make the soil particles tend to be condensed, produce new cementing material and improve and fill the pore in the soil to gain good physical and mechanical properties. The solidification process of soft muddy soil is accompanied by reversible physical process and irreversible chemical process, or a combination of both. Therefore, the solidifying mechanism of all solidify materials can be summarized into the following three types: physical-mechanical process, chemical process and physical-chemical process.

\subsection{Research status of physical and mechanical properties of solidified soft muddy soil}

The solidification effect of soft muddy soil is reflected by the physical and mechanical properties of solidified soil. Scholars at home and abroad often determined the 
physical and mechanical properties of solidified soil through indoor tests, as well as the influence law of solidify materials and environmental factors on the physical and mechanical properties. After

Table 1. Solidifying Mechanism of Main Solidifying Materials.

\begin{tabular}{|c|c|}
\hline Classification & Solidifying Mechanism \\
\hline Cement & $\begin{array}{c}\text { Hydration and hydrolysis reaction } \\
\text { of cement itself, effect between clay } \\
\text { particles and cement hydrates, } \\
\text { filling effect, cementation, } \\
\text { framework effect, } \\
\text { reinforcing effect of hydrates }\end{array}$ \\
\hline Lime & $\begin{array}{c}\text { Iron exchange reaction, Calcium } \\
\text { hydroxide crystallization reaction, } \\
\text { carbonation reaction, pozzolanic } \\
\text { reaction }\end{array}$ \\
\hline Silica fume & $\begin{array}{c}\text { Pozzolanic reaction, filling effect, } \\
\text { cementation }\end{array}$ \\
\hline $\begin{array}{c}\text { Industrial waste } \\
\text { pozzolanic reaction, filling effect }\end{array}$ \\
\hline Water glass & $\begin{array}{c}\text { Cementation, rapid hardening effect } \\
\text { and potentiation, filling effect }\end{array}$ \\
\hline $\begin{array}{c}\text { Ionic solidify } \\
\text { material }\end{array}$ & \begin{tabular}{c} 
Iron exchange reaction, cementation \\
\hline $\begin{array}{c}\text { Macromolecular } \\
\text { solidify material }\end{array}$
\end{tabular} Condensation polymerization, \\
\hline $\begin{array}{c}\text { Biological } \\
\text { enzyme solidify } \\
\text { material }\end{array}$ & Catalysis \\
\hline
\end{tabular}

solidify materials added, the moisture content, liquid plastic limit and pore ratio change. Chen Yixin ${ }^{[23]}$ conducted indoor tests such as sand tests, compaction tests and direct shear tests on the soft muddy soil solidified by quicklime. The results showed that adding quicklime could rapidly reduce the moisture content of silt soil, and with quicklime content growing the maximum dry density gradually decreases, the optimum moisture content increases and coefficient of compressibility decreases.

At present, there is no standard for the evaluation of solidification effect. Unconfined compressive strength, as the basic mechanical properties of solidified soil, is often regarded as the evaluation index of solidification performance by domestic and foreign scholars. Therefore, the research on mechanical properties mainly focuses on the influence factors of unconfined compressive strength of solidified soil, for example, the effect of initial moisture content, solidify material content and age on the strength of solidified soil. Ding Jianwen $^{[24]}$ proposed to deal with high moisture content the dredged mud with cement-phosphogypsum solidify agent. At the same time, taking into account the initial moisture content of silt, the phosphogypsum content and age, the unconfined compressive strength test of solidified soil was carried out, and the influence law of various factors was obtained. Guo $\mathrm{Yin}^{[25]}$ analyzed the influence law of different organic matter content, initial moisture content and age on the strength of solidified silt soil by unconfined compressive strength test, and the prediction model of strength of solidified silt soil is established.

\section{Existing problems and suggestions}

With the continuous efforts of domestic and foreign scholars, soft muddy soil solidification technology has produced a series of important research results. Especially in China, great progress has been made in solidify material, solidifying mechanism, compound solidify agent formulation, solidified soil constitutive model and numerical calculation analysis. However, there are still deficiencies in the following aspects:

(1) Due to the complexity of organic matter composition in soil, the current research on the effect of organic matter content on the performance of solidified soil remains qualitative rather than quantitative. It can be analyzed and studied quantitatively based on the organic matter itself, combined with soil chemistry

(2) There are few researches on solidification of the soft muddy soil in coastal areas of China. Traditional solidify agent is still used in most practical projects, and the solidification effect is not ideal. Therefore, it is necessary to carry out researches on the soft muddy soil in coastal areas, formulate solidify strategies for its characteristics, and develop new efficient compound solidify materials.

(3) The technology of solidification of soft muddy soil is widely applied in this field and the engineering quantity is huge, so mechanization construction method must be adopted. And different projects use different construction technology and equipment. So, it is necessary to carry out further researches on construction technology and develop special construction equipment suitable for different soil.

(4) Most of the research on the factors affecting the strength of solidified soil only consider the age and dosage. All factors should be comprehensively and systematically studied to establish a clear relationship between each factor and the strength of solidified soil.

( 5 ) So far, most of the researches has been analyzed from a single macro or micro level, which has limitations. It should be analyzed and studied in both macroscopic and microscopic aspects.

\section{Conclusion}

As the economy develops, hydraulic engineering, transportation, industrial and civil engineering and other businesses are in accelerating development and construction, leading to the increasing demand for land resources. There are numerous rivers and lakes in China, where soft muddy soil is widely distributed. In fact, there's a lot of silt in the project, and most of the time, it can't be used directly because of its specific engineering properties. How to deal with these wasted resources has become an important problem to be solved. It is the soft muddy soil solidification technology that solves this problem well. Through solidification technology, the properties of soft muddy soil can be improved to meet 
the engineering needs and be turned from waste to treasure and applied in various engineering fields. This not only has increased the economic efficiency and efficiency of land resources use, but it's also good for environment. The research and application of this technology will surely promote sustainable development in our engineering construction.

\section{ACKNOWLEDGMENT}

This paper is funded by the POWERCHINA science \& technology research project: (DJ-ZDXM-2015-12)

\section{References}

1. The Ministry of Water Resources of the People's Republic of China, GBJl45-90. China Planning Press (1991)

2. J.R Bao, W. Zhu, J.H Min, Technology of dredging and sludge treatment in small and medium-sized river regulation. Water Resources Protection, 31(1):56-68 (2015)

3. K. Huang, J.W Wan, G. Cheng, Y. Zeng, Testing study of relationship between water content and shear strength of unsaturated soils. Rock and Soil Mechanics, 33(9):2600-2604 (2012)

4. L. Shao, S.Y Liu, G.Y Du, M.F Gu, Experimental study on improvement of organic soil with cement and fly-ash. Journal of Engineering Geology, 16(03):408-414 (2008)

5. M.L Yan, Foundation treatment technology. Geological Publishing House (1999)

6. H.E Chen, A study on the behavior of organic matter in the progress of solidifying soft soil by cement. Jilin University (2006)

7. Z.P Fan, W. Zhu, C.L Zhang, Experimental study of influence of organic content on solidified dredging. Rock and Soil Mechanics, 26(8):1327-1334 (2005)

8. S. Tomohisa, K. Sawa, N. Maitoh, Hedoro hardening treatment by industrial wastes. Journal of the Society of Materials Science, 44(503):10231026 (1995)

9. A. Sezer, H.R Yilmaz, K. Ramyar, Utilization of a very high lime fly ash for improvement of Izmir clay. Building and Environment, 20(6):150-155 (2006)

10. Rose Wright Fox, James G. Macfarlane. Alternative Chemical Soil Stabilizers. Division of New Technology, Materials and Research, Department of Transportation (1993).

11. H. Tremblay, J. Duchesne, J. Locat, S. Leroueil, Influence of the nature of organic compounds on fine soil stabilization with cement. Canada Geotech, 39:535-546 (2002)

12. G.R Gao, J.C Li, Study of effect of reinforcing soft cohesive ground with portland cement. Journal of Engineering Geology, 4(1):45-52 (1996)
13. W.J Wang, X.R Zhu, Study on strength property of nanometer silica fume reinforced cemented soil and reinforcement mechanism. Rock and Soil Mechanics, 25(6):922-926 (2004)

14. X.S Zhuang, G.X Wang, A study on the characteristics of soils consolidated with industrial wastes. China Civil Engineering Journal, 38(8):114117 (2005)

15. C.X Huang, Study on cement-sodium silicatestabilized soil. Fuzhou University (2002)

16. W.B Jian, D. Zhang, C.X Huang, Micromechanism of cement-solium silicate-stabilized soft soil. Chinese Journal of Geotechnical Engineering, 35(S2):632-637 (2013)

17. B. Zou, R. Shen, Study on improving soft soil foundation with calcium acrylate. Railway Engineering, 5:10-12 (2000)

18. M.K Zhou, W.G Shen, Study on the performance of HS soft soil stabilizer. Journal of Wuhan University of Technology, 18(4):120-122 (1996)

19. X. Huang, S. Xu, J.G Ning, Experimental research on stabilized soft soils by alumina bearing modifier. Chinese Journal of Rock Mechanics and Engineering, 26(01):156-161 (2007)

20. J.G Ning, X. Huang, Experiment on structural formation and mechanism of strength increasing of stabilized soil. Journal of Beijing University of Aeronautics and Astronautics, 32(1):97-102 (2006)

21. Y. Guo, R.Q Xu, Y.C Shao, Study on mechanism of muddy soil stabilization. Journal of Zhejiang University(Engineering Science), 42(6):1071-1075 (2008)

22. C.L Zhang, Study of dredged sediments solidification mechanism based on water transfer model. Hohai University (2007)

23. Y.X Chen, B.T Wang, Y.Q Zhang, Experimental study on lime improved mucky soil. Science Technology and Engineering, 14(34):273-277 (2014)

24. J.WDing, S. Zhang, Z.S Hong, Experimental study of solidification of dredged clays with high water content by adding cement and phosphogypsum synchronously. Rock and Soil Mechanics, 31(9):2818-2822 (2010)

25. Y. Guo, Study on stabilization of muddy soil and mechanical properties of stabilized soil. Zhejiang University (2007) 